\title{
Genomic analyses of complex P. vivax infections
}

\author{
Ernest Chan ${ }^{1}$, Didier Menard ${ }^{2}$, John Barnwell ${ }^{3}$, Peter Zimmerman ${ }^{4}$, David Serre ${ }^{1^{*}}$ \\ From Challanges in malaria research: Core science and innovation \\ Oxford, UK. 22-24 September 2014
}

\section{Background}

The occurrence of multiple, genetically different, parasites in $P$. vivax -infected patients is well known but often conveniently disregarded. This complexity of infection has long been difficult tostudy due to a lack of molecular markers. Genome sequencing approaches could circumvent this limitation but require tailored analyses that have not always been implemented.

\section{Materials and methods}

Here, we analyze genome sequence data generated by us and others from $P$. vivax field isolates and monkeyadapted strains to characterize, across the entire genome, SNPs and sequence rearrangements. We also genotyped several blood samples infected by the same monkeyadapted strain to better understand the changes happening during the generation of these strains.

\section{Results}

All field isolates sequenced so far show evidence of complex infections, with typically $2-4$ strains present at $>5 \%$. We show that it is possible, empirically and analytically, to rigorously differentiate these parasites and reconstruct haploid genome sequences from these complex infections. Our analyses also demonstrate that the presence of distinct parasites in the original patient infection can lead to genetic heterogeneity in monkey-adapted strains.

\section{Conclusions}

Our findings reveal the pervasiveness of complex infections in P. vivax and show that erroneous genetic conclusions can be made if this aspect of the parasite's biology is not carefully addressed. We show that different approaches enable to rigorously assess complexity of infection and to separate strains within an infection. In addition to their relevance for genetic and genomic studies, our findings have important implications for in vitro and $e x$

${ }^{1}$ Cleveland Clinic, Cleveland, Ohio, USA

Full list of author information is available at the end of the article vivo studies of $P$. vivax and provide a framework to better design and control such functional studies.

\section{Authors' details}

${ }^{1}$ Cleveland Clinic, Cleveland, Ohio, USA. ${ }^{2}$ Institut Pasteur du Cambodge, Phnom Penh, Cambodia. ${ }^{3}$ Centers for Disease Control and Prevention, Atlanta, Georgia, USA. ${ }^{4}$ Case Western Reserve University, Cleveland, Ohio, USA.

Published: 22 September 2014

doi:10.1186/1475-2875-13-S1-041

Cite this article as: Chan et al: Genomic analyses of complex $P$. vivax

infections. Malaria Journal 2014 13(Suppl 1):041.
Submit your next manuscript to BioMed Central and take full advantage of:

- Convenient online submission

- Thorough peer review

- No space constraints or color figure charges

- Immediate publication on acceptance

- Inclusion in PubMed, CAS, Scopus and Google Scholar

- Research which is freely available for redistribution
() Biomed Central

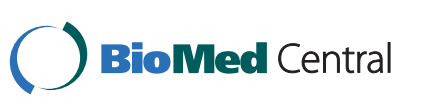

